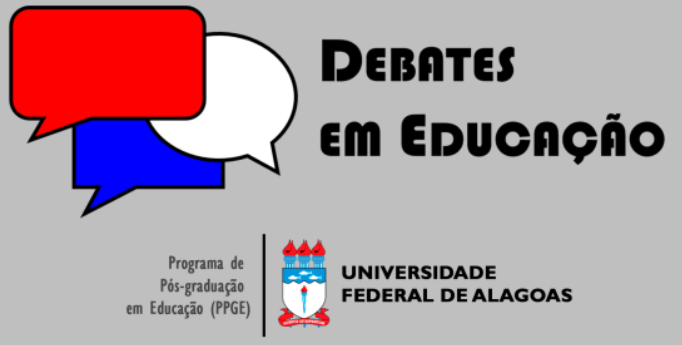

ISSN Eletrônico 2175-6600

Vol. 12 | N. 26 | Jan./Abr. | 2020

Matheus Marques Neumann

(9) iD

Universidade Presbiteriana Mackenzie (MACKENZIE) marquesneumann@gmail.com

Marcos Vinicius de Araújo

(9) iD

Universidade Presbiteriana Mackenzie (MACKENZIE) marcosaraujo3007@gmail.com

\section{O DIÁLOGO COMO AUXILIAR NO PROCESSO DE INCLUSÃO EM ESCOLAS QUE ATENDEM POPULAÇÕES EM CONDIÇÃO DE VULNERABILIDADE SOCIAL}

\section{RESUMO}

Esta pesquisa intervenção foi realizada com professores de uma escola Municipal situada no extremo leste da cidade de São Paulo, que lecionam crianças e adolescentes residentes em território de vulnerabilidade social a fim de investigar as dificuldades relacionadas à sua prática diária e oferecer um espaço de troca de experiência profissional. Foram feitas oito observações em uma sala de ensino fundamental II do sexto ano, e três encontros de grupos focais com os professores do Ensino Fundamental I e II. Nesse contexto, os dados revelaram dificuldades relacionadas à indisciplina e à continuidade da aula, à ausência de espaços de trocas de experiência profissional, apontando para a necessidade de criação de mais espaços dentro da escola em que estes tenham voz e possam discutir sua prática.

Palavras-chave: Professores. Inclusão. Vulnerabilidade Social.

\section{DIALOGUES AS AID IN THE INCLUSION PROCESS IN SCHOOLS ATENDING POPULATIONS ON SOCIAL VULNERABILITY CONDITIONS}

\begin{abstract}
This intervention research was conducted with teachers of a municipal public school located in the Far East of São Paulo city, who teach children and adolescents living in socially vulnerable territory in order to investigate the difficulties related to their daily practice and offer a space for exchange of professional experience. Were made eight observations in a sixth-grade elementary school teachers I and II and three encounters of focal groups with teachers that work in elementary I and II. In this context, the data revealed practical difficulties related to indiscipline and lesson continuity, absence of discussions spaces for sharing professional experiences, pointing to the need to create more spaces inside the school where the teachers have a voice and can discuss their practice.
\end{abstract}

Keywords: Teachers. Inclusion. Social Vulnerability.

Submetido em: 12/08/2019

Aceito em: 15/1 1/2019

Publicado em: 06/04/2020

do http://dx.doi.org//0.28998/2175-6600.2020v12n26p I24-142 


\section{INTRODUÇÃO}

No contexto brasileiro, nos últimos vinte anos, o processo de democratização escolar vem sendo responsável pela ampliação do acesso e da permanência de estudantes, tanto das camadas populares quanto com necessidades educacionais especiais à escolarização formal. Uma parcela significativa desses brasileiros até então não ultrapassava os primeiros anos da escolarização ou sequer entrava na escola, passou a frequentar as séries finais do Ensino Fundamental.

No caso de alunos com necessidades educacionais especiais, no Brasil, esse maior acesso decorre principalmente de um conjunto legal e normativo que indica a intenção de reestruturar a educação, ampliando seu acesso e estabelecendo a Educação Especial na perspectiva de Educação Inclusiva. Para isso, sustenta que os estudantes da Educação Especial devem ser matriculados preferencialmente em salas de ensino regular fazendo-se necessárias mudanças estruturais para garantia do acesso e permanência do aluno na escola, além de mudanças de atitude dos professores com relação ao ensino desses alunos, já que estes se apresentam muitas vezes como desafio aos profissionais.

Embora a legislação democratize o acesso à escola, quando se trata do contexto nacional, percebese a dificuldade de realização dos objetivos educacionais. Ainda se somam obstáculos à escola para a efetivação do processo inclusivo quando considerarmos o atendimento às necessidades educacionais de crianças e adolescentes residentes em territórios de vulnerabilidade social, independentemente de terem necessidades educativas especiais, TGB (Transtorno Global do Desenvolvimento) ou altas habilidades/superdotação.

Assim, a família residente em territórios de vulnerabilidade social, mais comumente localizados nas periferias das grandes regiões metropolitanas - onde as necessidades básicas como saúde, alimentação, moradia e segurança nem sempre são atendidas e o cotidiano é permeado por violência, inseguranças e pouco apoio institucional - possui a árdua tarefa de educar seus filhos para uma vida em sociedade e de inseri-los no mundo adulto, dificultado pelos fatores constituintes da vulnerabilidade que prejudicam a entrada e permanência de pessoas residentes nessas áreas em alguns âmbitos, especialmente no educacional.

Nesse segmento, as exigências do cumprimento da proposta de educar um aluno para conseguir formá-lo como cidadão e ainda obter os conhecimentos básicos estipulados recaem sobre o professor, cujo papel se torna cada vez mais sobrecarregado. A nova demanda de alunos que antes não estavam presentes nas escolas e agora possuem seus direitos garantidos pela legislação brasileira, misturadas às dificuldades de um território em condição de vulnerabilidade social, onde as famílias que além de carecerem de condições básicas de sobrevivência carecem também de uma rede de apoio social faz com que os professores tenham que lidar com essas demandas e desafios que thes foram impostos. Vale 
salientar que os professores e a instituição escolar não dispõem de recursos e apoio o suficiente para possibilitá-los a desenvolver novas formas de ensino que atendam às demandas dos alunos, às expectativas familiares, aos conteúdos que o MEC (Ministério da Educação) estabelece como necessários na escolarização e muito menos a esses fatores associados a uma educação na perspectiva inclusiva.

Portanto, a presente pesquisa assume a instituição escolar como a principal agência responsável pela distribuição de oportunidades para o desenvolvimento do indivíduo, além de oferecer possibilidades para a integração e mobilidade social ao ser dotada de recursos para o desenvolvimento e aprendizagem de novas habilidades e competências nos alunos durante o processo educacional.

Ademais, considerando a educação como um direito de caráter inquestionável, fez-se necessária uma intervenção dialogada com seus profissionais, submetidos diariamente a um cotidiano escolar estressante, que convivem com crianças e adolescentes em condições socioeconômicas e culturais precárias residentes em território de vulnerabilidade social, a fim de identificar as principais dificuldades desses profissionais ao atuarem para efetivar o direito de uma educação de qualidade, seguindo o modelo de inclusão, com equidade.

Ressalte-se que o presente projeto é parte integrante de um grupo de pesquisa certificado pela Universidade Presbiteriana Mackenzie intitulado "A escola nos processos educacionais inclusivos: um estudo em territórios de alta vulnerabilidade social".

Partindo do pressuposto de que os professores de escolas públicas - agentes presentes no cotidiano escolar dos alunos que possuem a função de mediador nos processos de aprendizagem - não têm auxilio e instrumentos o suficiente à sua disponibilidade para lidar com o processo de inclusão para que sejam garantidos processos educacionais de qualidade, e que a obrigação de organizar as condições de acesso aos espaços, aos recursos pedagógicos e à comunicação que favoreçam a promoção da aprendizagem e a valorização das diferenças, de forma a atender as necessidades educacionais de todos os alunos, pertencentes aos sistemas de ensino foi feita uma investigação a respeito dos possíveis impedimentos, demandas e dificuldades relacionadas à escola, aos recursos disponíveis, às condições territoriais e ao comportamento dos alunos que os professores e outros profissionais possuem ao lidar com o processo de inclusão educacional em territórios de vulnerabilidade social, além de verificar a eficácia da intervenção do pesquisador na escola com o objetivo de promover diálogos profícuos ao auxílio dos professores no processo de inclusão.

O número de matrículas na modalidade de educação especial teve um aumento de $9, \mid \%$ de 20 | | para 2012. De acordo com os dados do censo escolar de 2013, em 201 I eram 752.305 alunos, que se tornaram 820.433 em 2012 (BRASIL, 20 I3), evidenciando a necessidade dos sistemas de ensino público, escolas e profissionais da educação a se adaptarem à proposta da educação inclusiva. 
A esse contexto de aumento de taxas de matrícula e necessidade de reestruturação dos sistemas de ensino, somam-se as dificuldades provindas de um território em vulnerabilidade social, onde os impedimentos relacionados à renda, à família, ao transporte, à moradia, à saúde e ao lazer refletem no âmbito educacional. Esses fatores muitas vezes impossibilitam o acesso, a permanência e a aprendizagem durante o processo de escolarização de muitos alunos, que não carecem apenas de uma formalização do conhecimento, mas também de uma formação como cidadão e oportunidades no mercado de trabalho.

Sendo assim, a relevância desta pesquisa se deu no contato entre universidade e escola pública, possibilitando a intervenção na dura realidade dos profissionais da educação e colaborando para trazer ferramentas e recursos que possibilitem aos professores lidarem melhor com o processo de inclusão social, em escolas que atendem populações em condição de vulnerabilidade social a partir de reflexões, compartilhamento de estratégias de manejo em sala de aula e possíveis meios de atuação cotidiana com os profissionais do campo educacional. Isso é um passo para a efetivação de uma educação de qualidade com equidade.

Este trabalho elege como objetivos: identificar as principais demandas e dificuldades dos professores; no processo de inclusão educacional em escolas que atendam populações em condição de vulnerabilidade social; articular as atividades do Atendimento Educacional Especializado (AEE) com as atividades das salas de ensino regular; estabelecer intervenções que sirvam para que esses profissionais desenvolvam habilidades no processo de inclusão escolar; avaliar a eficácia do processo de intervenção.

\section{REFERENCIAL TEÓRICO}

A Conferência Mundial sobre Educação para Todos (UNICEF, 1990) art. Iº sustenta que "I . Cada pessoa - criança, jovem ou adulto - deve estar em condições de aproveitar as oportunidades educativas voltadas para satisfazer suas necessidades básicas de aprendizagem '”. Já no art. $2^{\circ}$ afirma que:

[...] lutar pela satisfação das necessidades básicas de aprendizagem para todos exige mais do que a ratificação do compromisso pela educação básica. É necessário um enfoque abrangente, capaz de ir além dos níveis atuais de recursos, das estruturas institucionais, dos currículos e dos sistemas convencionais de ensino, para construir sobre a base do que há de melhor nas práticas correntes.

Baseado nesta conferência e em outros eventos como a Declaração de Salamanca (BRASIL, 1994), a educação brasileira sofreu uma reformulação, especialmente, através da lei n. 9.394/96 - Lei de Diretrizes e Bases da Educação Nacional (BRASIL, 1996) que reconhece, em seu artigo 58, que a educação especial

\footnotetext{
' A aprendizagem, etapa fundamental da escolarização, é compreendida aqui como constituída tanto de instrumentos essenciais (como a leitura e a escrita, a expressão oral, cálculo e solução de problemas), quanto os conteúdos básicos da aprendizagem (como conhecimentos, habilidades, valores e atitudes) fundamentais para a sobrevivência, desenvolvimento, melhoria da qualidade de vida e continuidade no aprendizado (Declaração Mundial sobre Educação Para Todos, Jomtien, Tailândia, 1990).
} 
é uma modalidade de educação escolar oferecida preferencialmente na rede de ensino regular, para educandos com necessidades educacionais especiais.

Nessa perspectiva, a Política Nacional de Educação Especial na Perspectiva da Educação Inclusiva (BRASIL, 2008) busca a eliminação de barreiras para a participação completa de seu público-alvo, a saber: alunos com deficiência, transtorno global do desenvolvimento (TGB) e altas habilidades/superdotação. Para que isso se realize, é essencial o Atendimento Educacional Especializado (AEE) que conta com um profissional para realizar atividades complementares à aprendizagem na classe de ensino regular.

Em sua concepção sobre inclusão, Salvador (2006) elucida que o processo educacional inclusivo é aquele em que todos são atendidos e entendidos de forma significativa e ainda considera que nele as diferenças são tidas como sinônimos de riqueza, e não de limitações. Mantoan (2006) considera que esse processo traz benefícios para todos os alunos, com ou sem deficiências. Ainda afirma que se abre assim a possibilidade de provocar mudanças na relação de professores e alunos, onde estes mostrarão àqueles seus limites abrindo a oportunidade para que os profissionais os ultrapassem.

Nesse contexto, o professor tem ficado cada vez mais sobrecarregado. Para Esteve (I999 apud JUNIOR, E. G.; LIPP M. E. N., 2008) a comunidade e a família passaram a atribuir à escola e à figura do professor funções que muitas vezes os professores não estão preparados para exercer. Sobrinho (2002 apud JUNIOR, E. G.; LIPP M. E. N., 2008) destaca que, no posto de trabalho docente, há incompatibilidades entre as demandas da população infantil e do sistema educacional e os limites pessoais dos professores. Esse autor refere-se como exemplo, especialmente, ao comportamento dos alunos em sala de aula e às características próprias do atual movimento de inclusão na educação.

Além do mais, os profissionais possuem mais obstáculos para atingir os objetivos educacionais quando se trata de crianças e adolescentes de origem desfavorecida (BONAMINO; COSCARELLI; FRANCO, 2002; BATISTA, 20II). Esse fato aponta para uma dinâmica de retroalimentação entre desigualdade escolar e desigualdade social visto que, os indicadores educacionais pioram para todas as etapas de escolarização quando o foco são territórios que possuem condições sócio econômicas e culturais precárias. Pode-se dizer então que fatores como residir em territórios distantes, com frágeis estruturas de oportunidades, com acesso precário a serviços sociais, configuram territórios em vulnerabilidade social. Esse conceito é entendido nessa pesquisa como o risco ou a probabilidade de indivíduos, famílias ou comunidades serem feridos, lesionados ou sofrerem algum dano decorrente de mudanças ou permanências de condições, sejam elas externas ou internas. Pode se expressar nos sujeitos e na população em geral de diversas formas: como por fragilidade e impossibilidade de se defender contra mudanças do entorno; como falta de apoio institucional do Estado que se exime da responsabilidade de cuidar e fortalecer seus cidadãos; como indisposição que dificulta o aproveitamento das oportunidades 
presentes e como insegurança constante que paralisa, incapacita e desmotiva o pensar e agir fim de atingir melhores níveis de bem-estar (BUSSO, 200I).

Sant'Anna (2009) alerta que a vulnerabilidade social é um dos fatores que contribuem para um ciclo de recriação circular da pobreza, já que em determinadas condições os seus moradores são excluídos de alguns âmbitos, especialmente do educacional. Para o autor, isso acontece quando faltam mecanismos que permitam romper com essa situação de precariedade, seja por meio da melhoria da qualidade de vida gerada pelo trabalho ou pela educação. Para que não se repitam, as oportunidades de trabalho e de educação são o diferencial, rompendo com esse determinismo acerca da população em situação de vulnerabilidade, colaborando com o processo de transformação social.

Mendes; Almeida; Toyoda (20 II) destacam a importância de trabalhos de orientação dialogada no ambiente escolar, ressaltando resultados positivos ao término da intervenção. $\bigcirc$ estudo aponta que, de um modo geral, o ambiente de sala de aula se torna mais colaborativo e os professores revelam se sentirem mais confiantes sobre como lidar com as crianças com necessidades educacionais especiais em suas salas.

Dessa maneira, a presente pesquisa visou à identificação das principais demandas e dificuldades dos professores no processo de inclusão educacional em escolas que atendam populações em condição de vulnerabilidade social e à intervenção junto a esses profissionais para poderem refletir e compartilhar novas formas de lidar com as salas e alunos no processo de inclusão escolar.

\section{METODOLOGIA}

\section{I Participantes}

Os participantes foram alunos de uma sala de ensino regular (sexto ano, ensino fundamental II), 20 professores que lecionam em salas de ensino regular no ensino fundamental I e II, uma professora responsável pela sala de leitura e escrita e dois profissionais responsáveis pelo AEE (Atendimento Educacional Especializado) e pela Sala de Recursos Multifuncionais, todos de uma escola Municipal da periferia da cidade de São Paulo. Para manter a ética na pesquisa, foi utilizado um termo de assentimento para os alunos da sala observada, os quais concordaram com o prosseguimento da pesquisa, e o termo de consentimento livre e esclarecido tanto para os professores participantes quanto para um representante da instituiç̧ão. 


\subsection{Instrumentos e procedimentos}

Os instrumentos e procedimentos de coleta de dados utilizados ocorreram em duas etapas separadas exemplificadas abaixo.

\subsection{Etapa I: observações na sala de ensino regular.}

Procedimento: observação.

Instrumentos: roteiro de observação.

Descrição. Nesta etapa foram realizadas observações naturalísticas de oito aulas de 45 minutos cada, na sala de sexto ano do ensino fundamental II. Essas observações serviram como coleta de dados preliminar a respeito do cotidiano escolar que vivenciam os professores e isso possibilitou elaborar um roteiro de discussões com maior riqueza para ser discutido com os profissionais na etapa 2.

\subsubsection{Etapa 2: grupos focais com os professores.}

Procedimentos: grupos focais

Instrumentos: roteiros de questões semiestruturados.

Descrição. Nesta etapa, foram realizados três grupos focais que duraram em média Ih5min com os professores da escola que contou com a participação de 20 professores da sala de ensino regular fundamental I e II -, uma professora da sala de leitura e escrita e duas profissionais responsáveis pela Sala de Recursos Multifuncionais. A proposta do grupo foi que os profissionais discutissem questões sobre sua vivência em sala de aula, refletindo sobre as principais dificuldades e impedimentos que possuem no seu cotidiano escolar, possibilitando assim compartilhar estratégias utilizadas em sala e pensar sobre diferentes formas de encarar suas demandas cotidianas.

\subsection{Observação}

A observação é uma ferramenta privilegiada em investigações científicas no campo educacional. Este procedimento possibilita conhecer o fenômeno estudado, no momento e circunstância em que ele se produz, por via do contato direto entre pesquisador e acontecimento. Bránez (20 I3) define observação como olhar atentamente, e reitera a importância desse procedimento na compreensão de dados de um determinado contexto sociocultural e sua importância no âmbito escolar para se refletir, compreender e transformar as relações de ensino-aprendizagem. Os registros observados foram feitos seguindo um 
roteiro de observação pré-estruturado. Com o roteiro, há a vantagem de circunscrever e focar os objetos da observação tais como as interações entre aluno-professor e o uso de competências/ferramentas desenvolvidas ao longo da pesquisa e sua efetividade.

\subsection{Grupo Focal}

Dias (2000) aponta que os grupos focais são técnicas que reúnem em média 12 pessoas, estrategicamente escolhidas pelo pesquisador a fim de debater sobre conceitos ou determinado problema de pesquisa. Quando bem desenvolvidos, são boas ferramentas para coleta rápida de dados com baixo custo, com volume de informações qualitativas, significativamente grande. $\bigcirc$ Grupo Focal é uma técnica privilegiada para pesquisas com seres humanos, pois proporciona ao pesquisador a reunião em um mesmo espaço e durante um período de tempo um determinado número de participantes. $\bigcirc$ agrupamento permite a emergência de dados e o debate sobre determinado tema, a partir da interação e do diálogo, podendo coletar dados primordiais sobre um tema.(BACKES; COLOMÉ; ERDMANN; LUNARDI, 20 I I).

Depois, foram realizadas transcrições in verbatim (literal) dos grupos, e feita uma análise dos dados a partir do levantamento de categorias.

\subsection{Análise de Dados}

A presente pesquisa possui caráter qualitativo tanto nas partes de coleta, quanto na análise dos dados. Gonzalez Rey (2005) afirma que o qualitativo é complementar à pesquisa quantitativa porque aquele constitui vias de acesso a dimensões do objeto não acessíveis ao quantitativo. Chizotti (2003) afırma que o termo pesquisa qualitativa implica momentos de interlocução entre pessoas que permite o acesso às dimensões constituintes do objeto de pesquisa. Essa interlocução ocorre com a finalidade de obter, através desses contatos, significados expressos ou velados que podem ser captados a partir da atenção sensível do pesquisador.

Nesse segmento, o processamento das informações relativas à coleta dos dados da observação foi realizado de forma a descrever o que foi observado juntamente com percepções do pesquisador, e para os grupos focais foi feito, seguindo uma análise por categorias, explicada abaixo:

a) o pesquisador entrou em contato com os relatos dos grupos focais, a partir da leitura dos dados obtidos;

b) foram extraídas categorias com os temas que mais chamaram a atenção do pesquisador, de acordo com o objetivo da pesquisa; 
c) essas categorias foram, descritas, justificadas e relacionadas com base nos próprios relatos dos grupos focais;

Com base nesses passos, foram criadas onze categorias apresentadas em uma tabela, com nome, descrição e exemplo e a discussão dos resultados estabeleceu uma relação entre esta e as observações realizadas, apresentadas em relato descritivo.

\section{RESULTADO E DISCUSSÃO}

\section{I Observações em sala de aula}

As aulas observadas nesta sala de sexto ano foram as duas primeiras do período da tarde, em quatro dias distintos, sendo quatro observações ocorridas na primeira aula e quatro na segunda, contando com quatro observações nas aulas de matemática, e uma nas aulas de inglês, história, educação física e ciências. As aulas de matemática observadas foram duas de atividades em grupo, uma de avaliação e outra de planejamento e entrega de trabalhos; a de inglês foi uma aula de trabalho em duplas ou trios, a de educação física foi uma aula de avaliação e a de ciências foi uma aula expositiva. Todas as aulas contaram com a presença de pelo menos 25 estudantes, e a sala foi escolhida mediante as demandas institucionais, justamente por conta da dificuldade que os professores tinham com ela, nomeadamente por questões comportamentais como o barulho e agitação da sala.

Nas aulas de matemática, algumas dessas dificuldades se evidenciaram: na aula de atividade em grupo (duas primeiras aulas daquele dia da semana), cujo objetivo era a construção de um jogo de dominó utilizando régua e esquadro, os alunos do sexto ano pareciam sempre agitados, com várias conversas, barulhos e brincadeiras que beiravam ofensas entre eles. $\bigcirc$ professor teve dificuldades em iniciar a aula por conta do barulho. Quando se reuniram em grupos, alguns alunos pareciam estar mais engajados do que os outros nas atividades: enquanto alguns ficavam sentados, outros corriam pela sala, iam em direção a outros grupos, às vezes andando e às vezes correndo, e se provocavam. Conforme os estudantes terminavam suas tarefas e o horário do intervalo se aproximava, eles ficavam mais agitados, até serem liberados para sair. Nesta aula, o que me chamou a atenção foi o fato de que, embora houvesse dificuldades relacionadas ao comportamento dos alunos na sala, a atividade proposta estava sendo realizada pelos estudantes. Nas aulas de avaliação, de planejamento e entrega de trabalhos também houve dificuldades para serem iniciadas, por conta da agitação dos alunos. Na primeira, o professor assumiu uma postura mais rígida, não conversando muito com os alunos e tirando poucas dúvidas sobre a prova, alegando que os alunos já "sabiam o que fazer". Na segunda, um aluno com Síndrome de Down 
matriculado nesta sala, frequentou a aula, e o professor o colocou do lado de uma colega de classe, deixando então ambos sentados lado a lado. Ainda nessa aula, o professor estendeu o prazo de entrega dos trabalhos e, percebendo que alguns não fizeram o trabalho, dirigiu-se a eles, alegando que alguns deles que não fizeram o trabalho sem uma boa justificativa estariam se beneficiando. Alguns destes começaram a apresentar seus motivos, elevando novamente a agitação da sala. Foi observado também que o aluno com necessidade educacional especial estava fazendo atividades de raciocínio viso-espacial, copiando um modelo de figuras geométricas que não aparentava ter vínculo com a proposta do dia.

A aula de inglês (primeira aula do período) contou com dificuldades semelhantes às da de matemática, com o início de aula conturbado e a agitação dos alunos com brincadeiras e gritos. Para conseguir dar início à aula, o professor teve que dizer a dois alunos da sala para saírem desta por um tempo, enquanto reorganizava os alunos para sentarem em lugares distintos, separando-os. Assim, conseguiu explicar a proposta do dia, que era responder as perguntas de um jogo de tabuleiro em inglês. Enquanto passava nos grupos explicando o que deveria ser feito, alguns alunos levantavam das carteiras, faziam brincadeiras e chamavam uns aos outros. Depois que os estudantes que saíram voltaram à sala, o professor pediu que eles sentassem separados de seus grupos. Um deles ficou quieto, enquanto o outro continuou a gritar na sala e a chamar os outros colegas, sem fazer a atividade. No meio da aula, o aluno com necessidade educacional especial entrou na sala de aula, e o professor colocou sua carteira próxima à sua mesa, entregando-lhe jogos de quebra cabeça, novamente sem articulação com a proposta da aula. O professor, por estar dando mais atenção a este aluno, não observava as brincadeiras e bagunças na sala e uma estratégia que usou foi colocar um dos alunos que estava mais agitado na sala em um grupo de meninas. Este aluno modificou seu comportamento e deu mais foco à atividade.

$\mathrm{Na}$ aula de educação física (segunda aula do período), realizou-se uma avaliação onde as questões tinham relação com um trabalho que os alunos deveriam entregar nesse dia. A aula aconteceu depois de uma aula de matemática. Logo quando entrou, o professor ouviu um "palavrão" e perguntou quem tinha dito aquilo. A sala ficou quieta, e um aluno se manifestou dizendo que foi sem querer. $O$ professor orienta os alunos a guardarem o material e diz que retirará a prova em caso de cola, enquanto entrega as provas e dá mais algumas instruções, exigindo que os alunos sentem-se virados para frente, na postura "certa". $\bigcirc$ professor respondeu as dúvidas dos alunos em relação à prova, pedindo que eles levantassem a mão antes de falar, gerando uma organização. Dadas as orientações, a sala ficou em silêncio e quando este era rompido, os próprios alunos pediam uns aos outros para ficarem quietos, caso contrário seriam prejudicados com nota baixa. $\bigcirc$ professor disse para um dos alunos que iria para a direção caso ele não parasse de conversar, e, quando alegava não saber responder questões da prova, o professor disse que quem fez o trabalho saberia responder. Foi dito a um dos alunos que estava conversando que ele teria sua prova zerada, e este respondeu "ué, zera", e o professor retrucou dizendo que lembraria disso no 
conselho. Conforme os alunos acabavam as provas, a sala ficava mais agitada com barulhos, conversas e batuques.

$\mathrm{Na}$ aula de ciências (primeira do período) a atividade realizada foi uma atividade de leitura, em que os alunos puderam trabalhar novos conteúdos e conteúdos já passados no decorrer do semestre. Nesta aula, o silêncio na chegada do professor era mais presente do que nas demais. Logo que entrou na sala disse "boa tarde", os alunos responderam e logo depois ficaram em silencio. $\bigcirc$ aluno com necessidade educacional especial entrou na sala e um aluno mudou de lugar para que ele sentasse próximo à professora, e ficou com seus jogos de quebra-cabeças. A professora faz combinados com a sala trazendo atividades diferenciadas caso a sala se comporte bem. Nesse dia ela disse que uma atividade de forca com palavras de ciências já havia sido cancelada por conta do mau comportamento da sala. Quando percebia alguma movimentação ou conversa dizia frases como "Quem mandou sair do lugar? É assim que vocês querem brincar de forca amanhã?" e em geral conseguia silêncio. Nessa aula a professora delegou funções aos estudantes (dentre eles aqueles que mais são agitados e bagunçam), pedindo para buscarem os livros didáticos em outras salas e distribuírem para os outros alunos, podendo realizar assim a atividade de leitura. Outra estratégia utilizada pela professora foi perguntar aos alunos quem gostaria de ler os textos para a sala, e dividiu os textos de acordo com os alunos que levantaram a mão, dividindo e organizando as tarefas. Novamente aqui, aqueles alunos que bagunçam nas outras aulas se voluntariaram para realizar a atividade de leitura. Alguns dos textos lidos foram sobre os aparelhos meteorológicos, fenômenos atmosféricos como movimentos do ar e correntes de ar marítimas e continentais e a temperatura do ar, e campos magnéticos. A cada texto lido, a professora explicava a importância desse conteúdo e o próprio conteúdo em si, fazia perguntas para os estudantes e induzia as respostas iniciando as frases/palavras e deixando que os estudantes completassem; perguntava se os alunos entenderam o conteúdo (chegou a dizer "quem entendeu faz joinha") e reexplicava se fosse necessário, caso surgissem dúvidas.

A aula que sucedeu à aula de ciências foi de história, e a proposta era que os alunos respondessem as perguntas copiadas em uma folha de almaço, com base nos conteúdos trabalhados ao longo do semestre. As respostas das perguntas estavam nas anotações feitas dos alunos. Os alunos adiantados poderiam começar a fazer um mapa que estava localizado em uma das páginas do livro didático. A professora chegou à sala, explicou a proposta do dia e começou a entregar folhas para os alunos responderem as questões. Deu instruções de como manejar o lápis para melhorar as transposições dos mapas, enquanto o clima da sala ia ficando mais agitado, com alunos levantando e conversando. Ela disse que tiraria nota de quem estivesse de pé, mas ainda assim alguns estudantes continuaram se levantando e circulavam pela sala. Ela trouxe consigo o material didático e pediu a um aluno que os entregasse aos demais, para darem início às transposições no papel vegetal. $\bigcirc$ aluno com síndrome de Down esteve presente e fez seu quebra-cabeças, como sempre. A sala continuou com algumas movimentações e 
conversas, e os estudantes estavam fazendo o pedido. Algumas movimentações aconteciam em direção a outros alunos, que tiravam dúvidas entre si, pegavam materiais emprestados. Uma aluna chegou até a sentar junto com outra e escreveu em sua folha de almaço. A professora, quando percebeu, pediu para que sentasse "em seu lugar"; a aula seguiu até seu fim.

Assim, partindo das observações, foi possível ter um contato inicial com o que os professores passam em suas aulas, suas dificuldades e formas de manejar as aulas. Isso possibilitou a construção de roteiros que serviram de base para os três grupos focais, além de fornecer dados para que houvesse melhor diálogo entre pesquisador e professores.

\subsection{Grupos focais: temas tratados e apresentação das categorias.}

Os três grupos focais foram realizados com roteiro de questões semiestruturadas, que tratavam sobre a troca de experiências, dificuldades gerais e estratégias utilizadas no primeiro grupo, questões relacionadas à inclusão de alunos com deficiência, TEA e altas habilidades/superdotação no grupo dois e discussão de eventos observados nas visitas do pesquisador às aulas no grupo três. As siglas que apresentam os profissionais (PI , P2, P3 ...) são meramente ilustrativas e podem não representar a mesma pessoa caso o grupo seja outro. Abaixo a apresentação dos resultados em categorias na tabela I:

Tabela I - Categorias de análise com descrição e relatos das entrevistas

\begin{tabular}{|c|c|c|}
\hline Categoria & Descrição & Exemplos \\
\hline $\begin{array}{c}\text { Dificuldades } \\
\text { relatadas pelos } \\
\text { profissionais }\end{array}$ & $\begin{array}{c}\text { Nesta categoria } \\
\text { os profissionais } \\
\text { relatam algumas } \\
\text { de suas } \\
\text { dificuldades em } \\
\text { trabalhar nas } \\
\text { salas de ensino } \\
\text { regular }\end{array}$ & $\begin{array}{c}\mathrm{PI} \text {-“(...) você tem que lidar com a indisciplina também, para que o } \\
\text { outro tenha a mesma oportunidade de ouvir a aula, participar da aula e tudo } \\
\text { mais. " Grupo I }\end{array}$ \\
$\begin{array}{c}\text { cumprida conforme você tá vendo a autoridade presente ali... saiu a } \\
\text { autoridade, se por um minuto houve troca de aula, as regras de convivência } \\
\text { morreram, morreram por um minuto, e até você reestabelecer esse um } \\
\text { minuto de morte das regras de convivência..." Grupo I }\end{array}$ \\
$\begin{array}{c}\mathrm{PI} \text { - "Porque assim, quando começa o ciclo a coisa zera. E zera } \\
\text { porque não é uma coisa continua, não é linear para o aluno. Ele viveu num } \\
\text { mundo por cinco anos, e aí quando vai pro sexto ano ele vai viver em outro } \\
\text { mundo até o nono ano. " - Grupo 3 }\end{array}$ \\
\hline
\end{tabular}




\begin{tabular}{|c|c|c|}
\hline $\begin{array}{c}\text { Estratégias } \\
\text { remediadoras }\end{array}$ & $\begin{array}{l}\text { Estratégias } \\
\text { utilizadas após a } \\
\text { ocorrência de } \\
\text { um evento que } \\
\text { dificultou a aula, } \\
\text { com resultados } \\
\text { muito } \\
\text { dependentes da } \\
\text { turma e do } \\
\text { momento. }\end{array}$ & $\begin{array}{c}\text { P7 - "Conversa, individualmente, dá uma chance, dá outra, tem } \\
\text { paciência, respira fundo. Tem as questões de procedimento da escola, então } \\
\text { tem os cadernos de registro, que aí você já passa pra elas o nome do } \\
\text { registro... as questões da sala de aula: muda de lugar, porque as vezes } \\
\text { influencia, então você muda de lugar e resolve o problema... " Grupo I } \\
\text { P7 - "Encaminha para a direção antes de conversar com os pais } \\
\text { tenta resolver lá em baixo, não deu certo com você vamos ver se resolve } \\
\text { depois de conversar lá em baixo. Não deu certo, chama o pai, e às vezes } \\
\text { tem casos que chama o pai e depois não dá em nada. Ai você reelabora, } \\
\text { começa de novo..."Grupo I }\end{array}$ \\
\hline Estratégias eficazes & $\begin{array}{c}\text { Estratégias } \\
\text { profissionais que } \\
\text { colaboram para } \\
\text { o } \\
\text { prosseguimento } \\
\text { da aula com } \\
\text { resultados } \\
\text { positivos. }\end{array}$ & $\begin{array}{c}\text { PI - "É deixar claro, como é a aula, deixar bem claro quais são as } \\
\text { etapas que a aula precisa diariamente, que são os fixos... Aí vem, no início, } \\
\text { eu explico tudo "é assim, assim, a rotina da aula de ciências é essa. "- Grupo } \\
\text { PI2 - "Eu trabalho muito em grupo, então eu estabeleci que a sala } \\
\text { vai ter um líder da sala por dia, mesmo que não tenha trabalhos em grupo } \\
\text { (...) Quando eu vou falar, eu vou chamar a atenção, eu não chamo a } \\
\text { atenção da sala inteira, eu chamo o líder do grupo. "- Grupo I } \\
\text { PI - "O coletivo é conversar realmente, que eles se sintam à } \\
\text { vontade de realmente falar. Então "qual o problema dessa sala? ... eles } \\
\text { mesmos apontam os problemas, e eles mesmos apontam as soluções. "- } \\
\text { Grupo I } \\
\text { Pl - "Eu organizo esse momento [de ir ao banheiro]. Eles ficam lá } \\
\text { vai sair a fileira e todos têm que estar quietos na fileira. Então não é uma } \\
\text { questão do individual, é o coletivo. "- Grupo } 3 \\
\text { P2 - "Essa questão de ir ao banheiro também as vezes eu coloco } \\
\text { um código, pra ir no banheiro ou ir beber água, aí eles ficam super } \\
\text { empolgados e também só vai quem souber o código, e aí é alguma cosia da } \\
\text { atividade. "- Grupo } 3\end{array}$ \\
\hline $\begin{array}{l}\text { Aluno com } \\
\text { necessidade } \\
\text { educacional } \\
\text { especial na sala de } \\
\text { ensino regular }\end{array}$ & $\begin{array}{c}\text { Relatos dos } \\
\text { professores } \\
\text { sobre o trabalho } \\
\text { prático na sala de } \\
\text { ensino regular }\end{array}$ & $\begin{array}{c}\text { P6 - "...um aluno com deficiência dentro da sala de aula altera o } \\
\text { comportamento rotineiro da sala, independente do grau de deficiência ou } \\
\text { não, vai mudar, inclusive a sua forma de pensar a aula. Você vai ter que } \\
\text { pensar numa aula geral e numa aula para aquele aluno, no material de uso } \\
\text { geral e no material de uso especifico para aquele estudante com a } \\
\text { deficiência. " -Grupo } 2 \\
\text { P6 - "Outro caso é isso, às vezes o problema é aquilo que o PI } \\
\text { próprio contexto da sala de aula. "Grupo } 2 \\
\text { falou, às vezes o problema não é o estudante em si, a deficiência em si, é o } \\
\text { PI } 5 \text { - "porque é muito cansativo, e até pra gente, mesmo um } \\
\text { cadeirante que, no caso a menina que tava comigo, que não tem a } \\
\text { coordenação motora para escrever, mas tá alfabetizada, a gente adapta } \\
\text { atividade, mas não é o tempo todo que você consegue... o tempo todo } \\
\text { adaptando atividade..." - Grupo } 2 \\
\text { PI0 - "Ele não quer entrar. E quando ele entra, não quer sair } \\
\text { (todos riem). São dois trabalhos: pra ele entrar e pra ele sair. "- Grupo } 2\end{array}$ \\
\hline
\end{tabular}




\begin{tabular}{|c|c|c|}
\hline $\begin{array}{c}\text { Ocorrências } \\
\text { institucionais que } \\
\text { influem no } \\
\text { andamento de } \\
\text { aula. }\end{array}$ & $\begin{array}{c}\text { Eventos } \\
\text { cotidianos que se } \\
\text { passam na } \\
\text { instituição de } \\
\text { ensino que } \\
\text { modificam o } \\
\text { andamento das } \\
\text { aulas }\end{array}$ & $\begin{array}{c}\text { P6 - "eu já tenho em mente que os últimos cinco minutos ali, que } \\
\text { se for anterior ao intervalo ou alguma coisa assim, eu não posso fazer o } \\
\text { fechamento nesse tempo, tem que fazer um pouco antes. Então a aula já } \\
\text { chega a ficar um pouco mais curta. "- Grupo } 3 \\
\text { P4 - "O antes, são só cinco minutinhos, agora o depois do } \\
\text { intervalo, aí são vinte minutos pra você conseguir acalmar eles. Então você } \\
\text { perde mais aula do que no antes do intervalo. Antes do intervalo são só } \\
\text { cinco minutinhos, agora o depois do intervalo é mais. "- Grupo } 3 \\
\text { P9 - "E eu tenho a felicidade de dar aula para eles logo depois da } \\
\text { educação física... e eu vou entrar com história, um conteúdo que é } \\
\text { totalmente parado pra eles, inclusive o conteúdo não ajuda também. Então } \\
\text { você vai se virando nos trinta, a cada situação colocada. A nossa vida não é } \\
\text { fácil. "- Grupo } 3\end{array}$ \\
\hline $\begin{array}{l}\text { Necessidade de } \\
\text { planejamento } \\
\text { constante }\end{array}$ & $\begin{array}{c}\text { Relato dos } \\
\text { profissionais } \\
\text { sobre a aplicação } \\
\text { de estratégias e } \\
\text { replanejamento } \\
\text { nas salas de } \\
\text { ensino regular }\end{array}$ & $\begin{array}{l}\text { P7 - "Você também vai ficando desmotivado né? Porque pra mim } \\
\text { preparar a aula, e depois você chega lá e continua assim, prepara e não dá } \\
\text { certo, prepara e não dá certo, aí você vai ficando também desestimulado. "- } \\
\text { Grupo I } \\
\text { P6 - "No começo ele fez, a gente até discutiu com as professoras } \\
\text { da sala de recursos. Falei 'vamos tentar essa estratégia'. Funcionou um, dois } \\
\text { dias, umas duas, três vezes, mas depois acabou, ele não entra [na sala de } \\
\text { aula] de jeito nenhum. "- Grupo } 2 \\
\text { PI - "Então nesses planejamentos e nesses eventos diários, o } \\
\text { problema é ser diário, não é uma coisa que você consiga manter, não é uma } \\
\text { coisa que você consiga trazer uma estratégia que mostre algo linear pra você } \\
\text { algo que realmente você consiga a longo prazo. É a curto prazo, e a curto } \\
\text { prazo toda a sua estratégia dura exatamente } 45 \text { minutos porque na outra } \\
\text { turma você não sabe se aquela estratégia vai funcionar." -Grupo } 3\end{array}$ \\
\hline $\begin{array}{l}\text { Questões } \\
\text { familiares }\end{array}$ & $\begin{array}{c}\text { Relatos dos } \\
\text { profissionais } \\
\text { sobre a influência } \\
\text { das famílias na } \\
\text { escolarização. }\end{array}$ & $\begin{array}{l}\text { 'P4 -“... só que eles vêm com problemas lá de fora, porque o pai } \\
\text { bate na mãe, outro porque a mãe foi embora, outro porque o pai fugiu, } \\
\text { outro porque o pai tá na cadeia, então quer dizer, são coisas que estão além } \\
\text { da escola. " - Grupo I } \\
\text { PI - "Às vezes eles têm vontade e tudo mais, mas as vezes a falta } \\
\text { de organização mesmo dentro do núcleo familiar, não há esperança. - } \\
\text { Grupo I } \\
\text { P2 - "Então nem a família tá preparada pra lidar com isso. Então a } \\
\text { criança acaba ficando aqui nesse mundinho, porque a família não está } \\
\text { disposta a ter um trabalho a mais com essa criança" - Grupo } 2\end{array}$ \\
\hline $\begin{array}{c}\text { Insuficiência de } \\
\text { apoio aos } \\
\text { profissionais }\end{array}$ & $\begin{array}{c}\text { Relato dos } \\
\text { profissionais } \\
\text { afirmando apoio } \\
\text { insuficiente para } \\
\text { lidar com as } \\
\text { atuais demandas } \\
\text { na educação. }\end{array}$ & $\begin{array}{l}\text { P6 - “... o estagiário é para o desenvolvimento da aprendizagem } \\
\text { do aluno. Só que aí você tem um número X que pode ser contratado por } \\
\text { lei, e não é a necessidade do estudante que tá em jogo, é o número que } \\
\text { tem lá (...) então é, ele precisa, não tem um número, não tem, de } \\
\text { estagiários disponíveis pra sua escola. "- Grupo } 2 \\
\text { PI - "Não temos especialistas pra ajudar, então eles pegaram todas } \\
\text { essas demandas e jogaram para nós professores, e traz um monte de livro, e } \\
\text { a gente tem que ler tudo aquilo, e aprender por osmose como lidar com o } \\
\text { aluno, fazer com que a coisa aconteça e tudo. "- Grupo } 3\end{array}$ \\
\hline
\end{tabular}




\begin{tabular}{|c|c|c|}
\hline $\begin{array}{c}\text { Resultados } \\
\text { positivos no } \\
\text { processo de } \\
\text { escolarização }\end{array}$ & $\begin{array}{c}\text { Relatos dos } \\
\text { profissionais que } \\
\text { evocam } \\
\text { resultados } \\
\text { positivos no } \\
\text { decorrer da } \\
\text { escolarização. }\end{array}$ & $\begin{array}{c}\text { PI - "Então foi um trabalho de anos ali, pra poder chegar àquele } \\
\text { ponto de chegar e falar 'quem quer ler?' e todo mundo levantar a mão, você } \\
\text { tem que distribuir e os alunos mais sapecas lerem e tudo mais. É um } \\
\text { trabalho de ano, eles participaram, eles ficaram quietos, eles anotaram, mas } \\
\text { é o trabalho do ano todo ". - Grupo I } \\
\text { P5 - "Mas uma coisa é certa mesmo. A gente não tem noção } \\
\text { trabalhando com essas crianças deficientes, a gente às vezes passa o ano e } \\
\text { pensa "Meu Deus, eu não produzi nada, como é que ele tá, acho que ele } \\
\text { não melhorou, eu não consegui..." e quando passa esse período é que você } \\
\text { vê que você conseguiu alguma coisa. " - Grupo } 2 \\
\text { P4 - "Aí ele chegou em mim e falou assim, sabe, uma coisa que eu } \\
\text { fiquei assim, pasmo. Ele falou "Professor! Se eu ficar parado, concentrado, eu } \\
\text { consigo terminar a atividade!", sabe, ele tinha descoberto, terceiro ano tem } \\
\text { seis, sete anos."- Grupo } 3\end{array}$ \\
\hline $\begin{array}{c}\text { Ausência de } \\
\text { espaços para } \\
\text { diálogo profissional }\end{array}$ & $\begin{array}{l}\text { Relatos sobre a } \\
\text { falta de um } \\
\text { espaço na escola } \\
\text { que possa ser } \\
\text { proveitoso para } \\
\text { o diálogo entre } \\
\text { os profissionais. }\end{array}$ & $\begin{array}{l}\text { P7 - "(...) o que falta: a troca de experiências. A gente não tem essa } \\
\text { troca de experiências para saber como cada um tá lidando com os } \\
\text { problemas de cada turma. Às vezes a gente tá numa estratégia que não é a } \\
\text { mais eficiente. " - Grupo I } \\
\text { PI - “E eu acho que isso ajuda muito, a gente não tem esse espaço } \\
\text { pra saber o problema que o outro está passando em tal turma. " - Grupo } 2 \\
\text { PI - "Então assim, precisa de um tempo dentro da escola. A gente } \\
\text { precisa discutir um tempo pra gente pensar nesse público [alunos que } \\
\text { precisam de adaptação curricular]. "- Grupo } 2\end{array}$ \\
\hline $\begin{array}{c}\text { Relatos sobre o } \\
\text { efeito da circulação } \\
\text { de palavra e trocas } \\
\text { profissionais no } \\
\text { grupo. }\end{array}$ & $\begin{array}{c}\text { Discurso dos } \\
\text { professores } \\
\text { sobre os efeitos } \\
\text { produzidos pela } \\
\text { circulação de } \\
\text { palavra e troca } \\
\text { de experiências } \\
\text { profissionais. }\end{array}$ & $\begin{array}{l}\text { P5 -“Muitas vezes a gente pensa "ah, é comigo, sou eu", e quando } \\
\text { você vê outro colega falando então é da sala, é generalizado. Então dá um } \\
\text { alivio, e quando a gente desabafa e comenta e fala, então descarrega um } \\
\text { pouco o peso também né, então é bem bacana essa troca. "- Grupo } 2 \\
\text { PI -“E até mesmo essa troca de como um ajuda o outro né. Às } \\
\text { vezes você tá com num problema que outro professor daquela turma pode } \\
\text { te ajudar a enfrentar aquele problema com aquela sala, então eu acho que } \\
\text { aqui a gente ganha um corpo de grupo. Então a gente sai da individualidade, } \\
\text { do individualismo para assumir um grupo né. " - Grupo } 2 \\
\text { P2 - "A gente queria ter mais esses momentos né..."- Grupo } 3\end{array}$ \\
\hline
\end{tabular}

Fonte: elaboração própria (2020).

\subsection{Discussão dos resultados da observação e grupo}

De acordo com os resultados, as dificuldades relatadas pelos profissionais são diversas. Os relatos apontam maiores queixas às questões comportamentais dos alunos em sala de aula e, nos ciclos II, responsabilizam a transição de ciclo como um dos principais fatores contribuintes para a emergência dessas dificuldades. Essa transição é feita, na visão dos profissionais, de maneira descontínua, com mudanças na organização dos horários, tempo de aula e no número de professores. Esses fatores alteram a dinâmica da aula e influenciam negativamente no comportamento dos alunos dentro dessa dinâmica, evidenciado 
pela dificuldade em manter as regras de convivência e as queixas sobre indisciplina. Outras dificuldades enfrentadas pelos profissionais dizem respeito ao trabalho com alunos com necessidade educacional especial dentro da sala de aula, que demandam, em muitos casos, mais esforço dos profissionais no planejamento de atividades, além de uma atenção singular dentro da sala de aula. As questões familiares narradas pelos professores envolvem temas que nos permitem pensar na vulnerabilidade social como um fator limitante, que traz desesperança aos profissionais da educação por reconhecerem o limite de suas ações e do impacto negativo desses fatores na vida escolar dos estudantes corroborando pesquisas anteriores que afirmam a presença de mais obstáculos na educação de crianças e adolescentes de origem desfavorecida (BONAMINO; COSCARELLI; FRANCO, 2002; BATISTA, 20I I).

Essas variáveis associadas à limitação de uma rede de apoio profissional dentro de um território em vulnerabilidade social e à ausência de espaços em que possam discutir sua prática e trocar experiências contribuem para que os professores façam planejamentos e replanejamentos a cada dia e a cada aula, tendo que se readequar a cada nova situação emergente no momento para conseguir prosseguir com a aula. Esses fatores reiteram o que foi dito por Esteve (1999) e Sobrinho (2002), onde existem incompatibilidades entre as demandas profissionais e pessoais dos professores e seu papel acaba por ser sobrecarregado pelo excesso de demandas dessa profissão, ao lidar com questões nas quais não são preparados, reforçando o desgaste profissional (apud JUNIOR, E. G.; LIPP M. E. N., 2008).

Dessa maneira, a ausência de troca de experiências e de apoio contribuem para que algumas estratégias usadas pelos profissionais no curso das aulas sejam procedimentos escolares padrões exemplificadas na tabela pelas estratégias remediadoras - como: enviar o aluno para direção; contatar os pais; remanejar o posicionamento dos alunos em sala de aula e conversas individuais ou com todo o grupo, cujos resultados são muito variáveis. Pela narrativa dos participantes, são estratégias que têm efeito apenas imediato, sem nenhum efeito a longo prazo, necessitando assim serem constantemente usadas para que a aula possa prosseguir, gerando um desgaste profissional. Por outro lado, algumas estratégias apresentadas pelos profissionais pareceram ter resultados positivos ao longo do processo escolar. Tanto nas observações quanto nos grupos, as estratégias que mais contribuíram para o andamento das aulas envolviam organização, diálogo com os alunos permitindo que eles se manifestassem; estabelecimento de uma rotina de aula, deixando claro a proposta a ser trabalhada; compartilhamento de responsabilidades com os alunos tais como chamar a atenção da sala; entrega de materiais e leitura destes durante a aula. Nas observações foi notado que, muitos dos alunos que mais bagunçavam em algumas aulas, eram os mais colaborativos em outras, o que permite a formulação de que, ao conseguir direcionar a ação dos estudantes, os professores passam a ter colaboradores ativos no processo educacional.

A despeito das dificuldades enfrentadas com alunos com necessidade educacional especial e da modificação que causam no planejamento e desenvolvimento das aulas, percebe-se, por parte dos 
profissionais, que a compreensão dos fatores "problemas" nas salas vão além de uma compreensão individualizada. Nos relatos, o contexto da sala como um todo se sobrepôs à atribuição de um problema individualizado, e, embora as modificações causadas nas aulas possam exigir mais trabalho, tornando mais cansativa a vida dos professores, o processo inclusivo mostrou-se com bons resultados perceptíveis a longo prazo e com aprendizagem mútua entre educadores e educandos, corroborando as ideias de Mantoan (2006) no que se refere à inclusão, há a superação das limitações profissionais evidenciadas pelo contato com a diferença no espaço escolar.

As narrativas dos profissionais também relatam que, ao longo do processo educacional, existem resultados positivos em relação aos demais alunos. Estas indicam que a percepção dos resultados é, em sua maioria, a longo prazo, e que embora seja muito trabalhoso, o processo educacional é fundamental para a ocorrência dessas melhoras. Também foi destaque a relevância de um espaço em que os profissionais possam discutir sua prática cotidiana, trocar experiências e dialogar sobre suas estratégias e resultados em que se ganha um "corpo de grupo" e tem-se a oportunidade de diminuir o mal-estar e repensar maneiras de lidar com as dificuldades cotidianas, corroborando o que disseram Mendes, Almeida e Toyoda (20I I) a respeito da necessidade de intervenções dialogadas no ambiente escolar que trazem resultados positivos. Assim, os relatos apontam para a necessidade de criação desses espaços que possibilitem formação, reflexão e diálogo sobre as práticas profissionais dentro da própria escola para que assim possam transformá-las.

\section{CONSIDERAÇÕES FINAIS}

Com base nos resultados apresentados, a presente pesquisa cumpriu com a primeira parte do objetivo geral, a saber, investigar as principais demandas e dificuldades dos profissionais da educação de uma escola pública que atende populações em condição de vulnerabilidade social. Contudo, o estabelecimento de intervenções que pudessem ser aplicadas pelos profissionais em sua prática cotidiana ficou restrito às discussões em grupo, utilizando assim o pesquisador do grupo como um dispositivo de intervenção e coleta de dados. Dessa forma, não se pode saber dos reais efeitos na prática cotidiana do que foi discutido pelos professores, visto que o limite da coleta de dados era seus relatos e as observações realizadas antes da intervenção. Outro ponto a ser comentado foi sobre a impossibilidade de articulação entre o Atendimento Educacional Especializado (AEE) e as atividades da sala de ensino regular, visto que o espaço do grupo foi utilizado majoritariamente para discussão e estiveram presentes em apenas um dos grupos profissionais responsáveis por esse atendimento. Além do mais, os presentes resultados possuem uma amostra restrita de profissionais de uma escola da Zona Leste de São Paulo não podendo portanto, ter um caráter generalizado. Apesar das limitações citadas, o processo interventivo na escola foi bem 
avaliado pelos professores e constitui um passo importante para estabelecer laços entre comunidade e conhecimento acadêmico em que este consegue sair de suas fronteiras e impactar positivamente aqueles a quem se dirige. Para contribuir com esse laço, alguns estudos e modificações no estudo presente a serem realizadas podem ser sugeridas, como o estabelecimento de intervenções mais bem delimitadas dialogando com os professores, avaliando os resultados comparativamente entre o antes e depois das intervenções; estudo de professores que conseguem trabalhar de maneira colaborativa com alunos em sala de aula; verificação de estratégias de profissionais que relatam melhoras no trabalho com a sala ao longo do ano; intervenções a fim de formar um grupo de troca de experiência profissional, avaliando seus resultados e mais estudos a respeito das dificuldades vivenciadas pelos profissionais no cotidiano escolar.

Por fim, este estudo, tratando-se de uma pesquisa de Iniciação Cientifica em um contexto de congelamento de investimentos na educação, pode constituir-se enquanto contribuição na educação, ao apontar além dos problemas, também soluções viáveis dadas pelos profissionais às suas demandas cotidianas que podem ser compartilhadas através do diálogo e utilizadas por outros profissionais que trabalhem neste campo.

\section{REFERÊNCIAS}

BACKES, D.S.; COLOMÉ, J.S.; ERDMANN R. H.; LUNARDI, V. L. Grupo focal como técnica de coleta e análise de dados em pesquisas qualitativas. Mundo saúde [impresso], v. 35, n. 4, p. 438-442, 201 I

BATISTA, A. A. G. Alfabetização, leitura e esnino de protuguês: desafios e perspectivas curriculares. Revista Contemporânea de Educação, v.6, n. 12, p. 10-35, 2001.

BONAMINO, A; COSCARELLI, C; FRANCO, C. Avaliação e letramento: concepções de aluno letrado subjacentes ao SAEB e PISA. Educação \& Sociedade, Campinas, v.26, n.8। , p. 9| - I I3, 2002.

BRANÈZ, L. N. F.; Observação em sala de aula de Lingua Estrangeira: um processo inicial de reflexão crítica? the ESPecialist,São Paulo, vol. 34, no.2 p. I32- I 5 I, 2013.

BRASIL. Declaração de Salamanca e Linha de Ação sobre Necessidades Educativas Especiais. CORDE. Brasilia: 1994.

BRASIL. Lei n 9.394, de 20 de dezembro de 1996. Estabelece as diretrizes e bases da educação nacional. Ministério da Educação e do Desporto. Brasília: 1996.

BRASIL. MEC. Política Nacional de Educação Especial na Perspectiva da Educação Inclusiva. Brasília, 2008.

BRASIL. Ministério da Educação. Instituto Nacional de Estudos e Pesquisa Educacional Anísio Teixeira (INEP). Censo Escolar da Educação Básica. MEC/INEP. Brasília: 2013.

BUSSO, G. Vulnerabilidad Social: nociones e implicancias de políticas para latinoamerica a inicios del siglo XXI. Santiago, Chile: CEPAL, 200I. 
CHIZOTTI, A. A pesquisa qualitativa em ciências humanas e sociais: evoluções e desafios. Revista Portuguesa de Educação, v. 16, n. 2, p. 221-236, 2003.

DIAS, C. Grupo focal: técnica de coleta de dados em pesquisas qualitativas. Revista Informação e Sociedade. João Pessoa: Editora Universitária, v. 10, n.2, p. I4I - 158, 2000.

JUNIOR, E. G.; LIPP M. E. N. (2008) Estresse entre professoras do ensino fundamental de escolas públicas estaduais Psicol. estud. [online]., vol. I3, n.4, p.847-857, 2008.

MANTOAN, M.T.E. Uma escola de todos, para todos e com todos: o mote da inclusão. Disponivel em http://www.lite.fe.unicamp.br/papet/2003/ep403/uma escola de todos.htm Acesso em 03/0I/2017.

MENDES, E. G.; ALMEIDA, M. A.; TOYODA, C. Y. Inclusão escolar pela via da colaboração entre educação especial e educação regular. Educ. rev. [online]. V.I , n.4I, p.80-93, 201 I.

REY, F. G. Pesquisa qualitativa em psicologia: caminhos e desafios. I ed. Pioneira Thomson Learning. São Paulo: 2005.

SALVADOR, D.S.C.O.; MOURA, D. H.; SILVA, J. A. A.; MAIA, S. F. Processo educacional inclusivo: das discussões teóricas à necessidade da prática. HOLOS, v. I, n. I , p. II-23, 2006.

SANT'ANNA, M, J. O papel do território na configuração das oportunidades educativas: efeito escola e efeito vizinhança. In: Cerneiro, S. de S.; Sant'anna, M. J.Cidades, olhares, trajetórias. Rio de Janeiro: Garamond, 2009.

UNICEF. Declaração Mundial sobre Educação para Todos. Plano de ação para satisfazer as necessidades básicas de aprendizagem, Aprovada pela Conferência Mundial sobre Educação para Todos. Jomtien, Tailândia, 1990. 